\section{Imaginarios de la crisis de 2001 en el cine argentino. Análisis de la película Mercano el marciano*}

Imaginaries of the 2001 Crisis in Argentine Cinema. Film Analysis of Mercano el marciano

\section{Vicente Fenolt*}

\section{Resumen}

La crisis de 2001 influye en los imaginarios que circulan entre la sociedad argentina y se manifiestan en su producción cultural y mediática. Partimos de la base de que el imaginario es una creación incesante de figuras e imágenes que conforman lo que denominamos realidad social (Castoriadis 2007). El objetivo de este trabajo es averiguar cómo se representa en el cine animado cierto imaginario social relacionado con la crisis y con las consecuencias de la implantación del sistema neoliberal en

\footnotetext{
This project has received funding from the European Union's Horizon 2020 research and innovation programme under the Marie Skłodowska-Curie grant agreement No. 645666.

** Universidad de Valencia, vicente.fenoll@uv.es
}

Argentina. A partir del análisis del discurso de la película de animación Mercano el marciano (Juan Antín, 2002), establecemos qué elementos de la crisis se problematizan. Las conclusiones del trabajo señalan que el discurso de la película contrasta con el ofrecido en el Nuevo Cine Argentino, ya que emplea un discurso pedagógico y contestatario que legitima el uso subversivo de la fuerza, señalando directamente a los culpables de la crisis.

Palabras clave: Argentina, crisis, cine de animación, Mercano, imaginarios

\begin{abstract}
The 2001 crisis influences the imaginaries that circulate between the Argentine society and they are manifested in its cultural and media production. We start from the view that the imaginary is an incessant creation of figures and images that conform what we call social reality (Castoriadis 2007). The goal of this work is to find out how a certain social imaginary related to the crisis and the consequences of the implantation of the neoliberal system in Argentina are represented in animated cinema. Through an analysis of the discourse of the animated film Mercano el marciano (Juan Antín, 2002), we establish which elements of the crisis are problematized. Findings show that the discourse of the film contrasts with that offered in the New Argentine Cinema, because it uses a pedagogical and anti-establishment discourse that legitimizes subversive violence, pointing directly to the main culprits of the crisis.
\end{abstract}

Key words: Argentine, Crisis, Animated Film, Mercano, Imaginaries 


\section{Introducción}

Elcineesun medio decomunicaciónquefunciona como una extraordinaria caja de resonancia del imaginario social, que refleja las mutaciones que se producen en las representaciones colectivas (Imbert 2006). Junto con la prensa, la radio y la televisión, el cine constituye un instrumento de reproducción de ideología e imaginarios sociales compartidos por la audiencia. De este modo, los medios pueden ayudar a 'cristalizar un conjunto de significaciones en torno a un mundo posible y sus particularidades políticas, económicas, sociales y culturales' (Mayorga, del Valle y Browne 2013: 492).

El imaginario social es un conjunto de representaciones vinculadas a la imagen que el sujeto tiene del mundo, del otro y de sí mismo (Imbert, 2006). Sin embargo, en periodos de crisis 'se intensifica la producción de imaginarios sociales competidores; las representaciones de una nueva legitimidad y de un futuro distinto proliferan, ganan tanto en difusión como en agresividad' (Baczko 1999: 29). Como señala Alejando Grimson (2004), la experiencia devastadora del desempleo, el hambre y la recesión que desencadenó la crisis de 2001 se ha convertido en un núcleo configurativo de la imaginación y los sentimientos de los argentinos.

En este contexto, el neoliberalismo conforma un imaginario social predominante, donde el individualismo, la desconfianza del estado y la lógica de la mercancía lo envuelve todo (Díaz 2015). Adicionalmente, Maristella Svampa (2005) señala que, a pesar de la consolidación de un modelo de ciudadanía fragmentado, patrimonialista y consumidor, la naturalización de la relación entre globalización y neoliberalismo origina importantes tensiones y conflictos en la sociedad argentina que desencadenan el cuestionamiento del modelo dominante y la aparición de nuevas formas de prácticas políticas de acción colectiva.

En el ámbito del cine de animación argentino, encontramos reflejada de forma tangencial la problemática de la crisis y sus consecuencias en películas como The Planet (Pablo Rodríguez Jáuregui, 2002), Ánima Buenos Aires (María Verónica Ramírez, 2012) o Metegol (Juan José Campanella, 2013). Igualmente, algunos cortos de animación incorporan críticas implícitas a la tecnología (Teclópolis, Javier Mrad, 2009) o al modelo de producción capitalista (El empleo, Santiago 'Bou' Grasso, 2008; Luminaris, Juan Pablo Zaramella, 2011). Sin embargo, en la película Mercano el marciano (Juan Antín, 2002) disponemos de un caso paradigmático para el estudio de la representación explícita de los imaginarios sociales de la crisis argentina.

En primer lugar, el tema de la película se centra de lleno en la debacle de 2001 y su producción es coetánea a la crisis. Es decir, se trata de una crónica en clave de ciencia ficción, pero con un trasfondo realista que da cuenta, casi en directo, de la situación que están viviendo tanto los protagonistas de la historia como los creadores de la misma.

En segundo lugar, desde una perspectiva formal, como señala Santiago Grasso (en Godfrid 2009), la utilización de la animación permite al autor desarrollar ideas que son difíciles de plasmar en cine de acción viva. De tal forma que podemos pensar las animaciones 'como discursos capaces de poner en relieve, de manera particular, lo que sucede en una sociedad' (Pelli 2012: 57). 
Por último, se trata de una producción que cuenta con la subvención del Instituto Nacional de Cine y Artes Audiovisuales (INCAA) y con el apoyo de la Fundación Universidad del Cine. De esta manera, al tratarse de una producción independiente, la película no está constreñida por las limitaciones que impone la lógica comercial de la industria cultural y cuenta con mayor libertad para expresarse y desarrollar el contenido. En este sentido, como afirma Mónica Kirchheimer, Mercano el marciano es considerada como una película de culto en el ámbito de la animación argentina, 'tanto por su temática, claramente adulta, como por su tratamiento plástico' (2012: 6).

\section{Objetivos y planteamiento metodológico}

El propósito de este trabajo es analizar cómo se representa el contexto político, económico y social de la crisis argentina de 2001 en el ámbito del cine de animación. En particular, queremos investigar los imaginarios sociales de la crisis que confluyen en la película de animación Mercano el marciano (Juan Antín, 2002). Partimos de la base de que el clima de convulsión social que sufre Argentina durante el cambio de siglo genera un sistema de discursos vinculados a los imaginarios sociales de la crisis que se cristalizan en la 'expresión simbólica en distintos lenguajes artísticos producidos en ese contexto' (Amado, 2009: 16). De tal forma que 'uno de los efectos de la crisis ha sido promover cambios en el espacio imaginario de la nación' (Page 2009: 110).

Consideramos que los productos culturales incorporan elementos del proceso histórico y social en el que se circunscriben (Williams 1997) $y$, por tanto, las películas 'testimonian, mas o menos, un estado de sociedad' (Sorlin 1991: 85). De esta forma, el análisis del discurso nos permite describir los imaginarios que reproduce el film y las huellas de las condiciones sociales productivas en que se genera (Verón 1998).

Como apunta Cornelius Castoriadis, las significaciones imaginarias sociales utilizan lo simbólico como un instrumento para manifestarse y materializarse. De este modo, tanto en las metáforas como en las alegorías más sutiles o disparatadas existe una referencia identitaria, 'punto de una red de referencias identitarias, aprehendido él mismo en el magma de las significaciones y referido al magma de lo que es' (2007: 541). En tal sentido, los imaginarios son construcciones mentales socialmente compartidas con el propósito de dar sentido al mundo y a la sociedad (Baeza 2003, 2000).

En cuanto al imaginario social de la crisis argentina, Mayorga, del Valle y Browne plantean que 'corresponde a una red de relaciones de sentido construida sobre la base de la incertidumbre, la desconfianza, la violencia y la ingobernabilidad' (2013: 512-513). El estudio de la representación en el cine de los distintos tipos de construcciones sociales relacionados con la crisis es pertinente porque el concepto de imaginarios sociales es consustancial a la idea de institucionalización social de 'determinadas visiones, de determinados discursos y de determinadas prácticas con efectos sociales y, por último, hasta de determinados estilos de la acción social' (Baeza 2008: 190).

Dado que el imaginario social instituido se repite una vezcristalizado paragarantizarlacontinuidad de la sociedad hasta que un cambio histórico lo modifica o reemplaza radicalmente (Castoriadis 
1999), consideramos oportuno el análisis del discurso de Mercano el marciano, ya que se gesta en pleno proceso de convulsión social, cuando se abre una ventana de oportunidad para la irrupción de nuevos imaginarios. Los imaginarios emergentes pueden competir por la hegemonía con los imaginarios dominantes, que comprenden aquello que 'un sector social triunfante, una elite, considera adecuado para responder a los desafíos tanto coyunturales como durables de la historia' (Baeza y Silva 2009: 37).

En consonancia con la fundamentación teórica, implementamos una metodología cualitativa para analizar las construcciones comunicativas simbólicas de los imaginarios sociales que se materializan en Mercano. Realizamos un análisis crítico del discurso que se 'centra en los problemas sociales, y en especial en el papel del discurso en la producción y en la reproducción del abuso de poder o de la dominación' (van Dijk 2003: 144). Desde una perspectiva inductiva, buscamos averiguar sobre qué elementos críticos se sustenta la película y establecer el catálogo de víctimas y culpables de la crisis que subyacen en los hilos discursivos del relato fílmico. En consecuencia, planteamos las siguientes preguntas de investigación, adaptadas de los instrumentos para el análisis de discurso propuestos por Jäger (2003):

- ¿Qué crítica subyacente puede hallarse en la película?

- ¿Cuál es la perspectiva de futuro que establece la película?

Siguiendo la propuesta metodológica de Salinas, Stange y Santa Cruz, el análisis de la postura discursiva del filme se operacionaliza en dos niveles: descriptivo-narrativo e inferencial-contextual. En primer lugar, en el siguiente apartado se analiza el nivel descriptivo, poniendo el foco en 'delimitación y tipos de conflicto; representación de los actores históricos; relación entre estos actores y los personajes dramáticos; valoración de los hechos históricos; puesta en escena' (2013: 124). En segundo lugar, en las conclusiones se aborda el nivel inferencial del análisis. 'En este nivel se interpretarán los resultados del análisis precedente en referencia a los marcos históricos y sociales de sentido en el que la composición del filme adquiere relevancia' (2013: 124). De esta manera, se contextualiza las relaciones de sentido del discurso de la película en el ámbito de sus condiciones de producción.

\section{Análisis de Mercano el marciano}

Mercano el marciano es una película de animación argentina que surge como adaptación cinematográfica de la serie televisiva homónima, emitida a finales de los noventa en la cadena de cable Much Music. El film se estrena en octubre de 2002, por lo que el contexto de su posproducción se desarrolla durante los momentos más duros de la crisis. Como señala Juan Antín en una entrevista al diario El Clarín:

\footnotetext{
El guion se escribió en el '99, y cuando estábamos en posproducción fue lo del corralito. En la tele se veían imágenes que habíamos animado hacía meses. Ya en el libro que escribimos con Lautaro Núñez de Arco estaban los saqueos, el Banco Gidos con personas durmiendo afuera, la gente comiendo basura. Las llamamos escenas premonitorias. Es que acá la realidad supera a la ficción ${ }^{1}$.
}

El Clarín, (28-09-02). "De humanos y marcianos". Disponible en: http://edant.clarin.com/diario/2002/09/28/c-01202.htm 
$\mathrm{Ha}$ recibido numerosos premios a su paso por festivales de todo el mundo, entre los que destacan: Premio del público en el Festival Internacional de Cine de Sitges (2002), Premio especial del jurado en el Festival de Cine de Animación de Annecy (2002) y Premio al mejor largometraje en el Festival Animadrid (2003). Asimismo, fue premiado con el Cóndor de plata al mejor largometraje animado, otorgado por la Asociación de Cronistas Cinematográficos de la Argentina (2002).

La película cuenta la historia de Mercano, un marciano que viaja a la Tierra para vengarse de la muerte de su mascota, aplastada en Marte por la sonda espacial Voyager. El protagonista llega a Buenos Aires en plena crisis económica y se queda atrapado al destruirse la nave durante el aterrizaje. Existen referencias explicitas a la ciudad, como la entrada del Subte de la calle Uruguay, la calle Lavalle y Florida, el Obelisco o el aterrizaje de la nave marciana, en el que se ve cómo se aproxima a la Tierra, se dirige hacia Argentina y se estrella finalmente en el centro de la Capital Federal. El contexto histórico es también reconocible por la reproducción de imágenes vinculadas a ese periodo: saqueos de comercios, gente comiendo de la basura, familias viviendo en la calle, predicadores apocalípticos, etc.

Desde su refugio en los túneles del subterráneo bonaerense diseña con una computadora un mundo virtual en 3D que recrea su planeta, con el fin de aplacar su nostalgia ante la imposibilidad de regresar a Marte. En este espacio virtual, Mercano conoce a un niño llamado Julián, con el que establece una relación de amistad. El padre de Julián pertenece a la Corporación, una empresa multinacional que controla la economía mundial y que decide apropiarse del invento del marciano para mercantilizarlo y sacarle rendimiento a nivel global. De este modo, la Corporación engaña a Mercano con la falsa promesa de devolverlo a su planeta y lo secuestra para aprovechar el potencial de la inteligencia extraterrestre. Julián libera a su amigo marciano y consigue escapar con él, teletransportándose por casualidad a la casa de Teo, Rino y Poxi, un grupo de neoluditas influenciados por el manifiesto de Unabomber. Juntos deciden volver a la Corporación para destruir los servidores y acabar con el control tecnológico.

Finalmente, ante una derrota inminente un miembro de la Corporación decide destruir el planeta, gracias a una carga explosiva que había camuflado en todas las computadoras que habían diseminado por todo el mundo. En ese instante, los amigos marcianos de Mercano aparecen en una nave extraterrestre para rescatarlo, introducidos por una delirante escena musical con reminiscencias de los Monty Python. Los marcianos desaparecen justo antes de una gran explosión que acaba con el planeta Tierra.

A pesar de mostrar una visión negativa de la naturaleza humana y del final apocalíptico, los aspectos irónicos de la película predominan sobre los patéticos. La estética utilizada y la combinación de crítica y humor recuerdan a series de animación como Beavis and Butthead (Mike Judge, 1993-2011), Futurama (David X. Cohen y Matt Groening, 1999-2013), Southpark (Trey Parker, Matt Stone y Brian Graden, 1997-) o The Simpsons (James L. Brooks, Matt Groening y Sam Simon, 1989-). En tal sentido, Mercano es una combinación de géneros, en los que se relata con humor una historia de ciencia ficción atravesada con un trasfondo dramático, que 
muestra la crisis social de la Argentina de forma realista y explícita. Como señala Jameson, esta combinación de géneros responde a la desdiferenciación de niveles sociales, acentuada en un momento de máxima polarización en la distribución de la riqueza en el país: 'the new post-generic genre films are allegories of each other, and of the impossible representation of the social totality itself' (1995: 5).

El análisis del discurso de Mercano revela tres elementos principales sobre los que se articula de manera subyacente la crítica de la película: la sociedad, la globalización y el progreso.

\subsection{Sociedad}

La Corporación utiliza la tecnología para crear una dependencia en la población, a la que quiere seducir mediante eslóganes como 'la felicidad está al alcance de sus labios', con los que trasformar a los ciudadanos en consumidores y a Internet en un templo del consumo virtual. En este sentido, la película muestra a la sociedad de manera ambivalente. Por un lado, es la víctima del mercado y de las corporaciones, que intrigan para someterla. Por el otro, es corresponsable de la situación, al aceptar de forma sumisa e incluso festejar el advenimiento del consumismo y la reducción del ciudadano a consumidor tecnológico. Como señala Castoriadis (1991: 45): 'la avalancha de la tecnociencia contemporánea se alimenta del apoyo activo de los pueblos y no de una simple tolerancia'.

Esta recriminación se enfatiza cuando se confrontan las imágenes de la gente arriba en sus casas frente a la computadora, conviviendo en el mismo espacio y tiempo, con las imágenes de pobreza severa abajo en las calles de Buenos
Aires. A través de una serie de panorámicas de la ciudad, se contraponen estos dos mundos, con el único sonido de fondo del teclear en los teclados de las computadoras. La alienación, el individualismo, la fragmentación social y la sumisión ante las nuevas tecnologías al servicio de la Corporación se hacen patentes con los planos que muestran familias enteras, desde el abuelo hasta el bebé, navegando en silencio frente a la pantalla de la computadora, que funciona como un panóptico invertido. Como señala Raúl Manrupe, Mercano 'refleja la ruptura de códigos generalizada en todos los aspectos de la vida argentina durante la segunda presidencia menemista. Impunidad, descaro, nihilismo y cierto hedonismo (truncado a fines del 2001) son conceptos que consciente o inconscientemente manejan sus guiones' (2004: 118).

Mientras los que han sobrevivido a la crisis permanecen alienados de la realidad social del país dentro del mundo virtual de la Corporación, los desposeídos mendigan en las calles, incluso pernoctan a la intemperie a los pies del Obelisco. De este modo, la extensión de la decadencia al mismísimo emblema capitalino funciona como una sinécdoque que refleja el estado de pauperización en el que se encuentra el país, que permanece impasible a la debacle social. En este sentido, aunque el film utiliza los símbolos nacionales como ya lo hiciera el Nuevo Cine Argentino (NCA) en películas como Pizza, birra, faso (Adrián Caetano y Bruno Stagnaro, 1998), las imágenes no se limitan a mostrar la marginalidad en el corazón de Buenos Aires, sino que contienen una denuncia contestataria que interpela a la conciencia de los argentinos.

La crítica de la película se dirige también hacia la juventud argentina, ya que incluso los adolescentes que aparecen en la película 
en contra del sistema son un nido de contradicciones. Por un lado, rechazan el control tecnológico, pero, al mismo tiempo, 'necesitan las computadoras'. En definitiva, el único grupo de jóvenes que toma conciencia de la situación está más preocupado por conseguir cerveza fría que por emprender alguna acción para provocar un cambio. Como señala Antín en la entrevista a El Clarín, el grupo de neoluditas 'son una crítica a nuestra generación, que está al tanto de todo lo que pasa, pero nadie hace nada. En realidad, estamos más pensando en irnos a Barcelona'.

\subsection{Globalización}

Junto a la actitud pasiva de la sociedad, aparecen señalados, reiteradamente, dos responsables de la situación: la globalización y el progreso. Según apunta Joanna Page (2009), los sucesos de la crisis movilizaron una serie de discursos nacionalistas alrededor de la experiencia compartida del desastre económico que sufrió el país y establecieron un conjunto de enemigos comunes, entre los que se encuentran el Banco Mundial, el FMI, así como las empresas multinacionales que tomaron el control de muchos de los activos argentinos durante el programa de privatizaciones de Menem.

En la película, la crisis se traduce en un profundo recelo de los personajes hacia la globalización, entendida como una herramienta de las multinacionales norteamericanas para tener acceso a los mercados de los países emergentes. En este sentido, se desarticula en la sociedad argentina el discurso de que la globalización y el neoliberalismo presentan una oportunidad de ascenso social (Svampa, 2005). Como reconoce el propio Antín en una entrevista a Página/12: 'nuestra historia se enmarca de algún modo con el movimiento de antiglobalización’2.

La crítica a la globalización y al sistema neoliberal se concreta de manera explícita en las referencias a la Corporación. El carácter internacional de la misma queda patente por los distintos acentos y la composición interracial de los miembros del consejo de administración. La película pone rostro al odiado mercado, aunque los personajes aparecen estereotipados mediante nombres que representan las distintas divisiones de una multinacional: señor Alimenticio, señor Economía, señor Genética, señor Informática, señor Marketing y señor Tecnología. La sociedad argentina, la población mundial, incluso el extraterrestre Mercano, todos son explotados por la Corporación. Cualquier elemento con potencial para ser mercantilizado es deglutido por la multinacional y transformado en una herramienta de control y de generar beneficios. La apropiación de los bienes comunes se realiza sin ningún tipo de escrúpulos, incluyendo el robo, el engaño y el secuestro. Incluso el idílico mundo virtual que desarrolla Mercano es trasformado tras la toma de control de la Corporación en un espacio mercantilizado donde se cobra a los usuarios por el acceso a distintos servicios.

Las corporaciones multinacionales aparecen en la película como las verdaderas responsables de la situación y culpables, en último término, de la destrucción de la Tierra. Encontramos varios ejemplos en los que se retratan distintos aspectos negativos del sistema neoliberal, en general, y de las corporaciones, en particular. La obsesión por ampliar el mercado ad æternum

Página/12, (10-10-02). "Las tribulaciones de Mercano, el marciano varado en la Argentina". Disponible en: http://www.pagina12.com. ar/diario/espectaculos/6-10884-2002-10-01.html 
sin ningún tipo de escrúpulos se concreta con el engaño y secuestro de Mercano, sometido por la Corporación para extraer todo su potencial productivo. También queda patente el afán de la multinacional por controlar a la población mundial: 'le venderemos a todo el planeta, será nuestra clientela global cautiva'. De esta manera, se constata la idea de que el capitalismo con cada crisis: 'sufre una mutación para pasar a una esfera más amplia de actividad y un campo más vasto de penetración, control, inversión y transformación' (Jameson 2002: 184).

La crítica al neoliberalismo y su vínculo con la explotación del ser humano se sintetiza en la frase: 'habría que explotar el tiempo que la gente pasa frente a sus computadoras'. A posteriori, se aprehende que el verbo explotar es utilizado de forma polisémica y que la explotación de los humanos comprende todas las acepciones de la palabra. Igualmente, la idea de que el poder político ha desaparecido disuelto en el entramado neoliberal la encontramos en una reunión del consejo de administración de la Corporación, donde a la interpelación: 'Eso nos traería problemas con el Gobierno', el señor Marketing responde: ‘¿Cuál Gobierno, che?’.

\subsection{Progreso}

La película muestra una concepción de progreso que está en sintonía con la visión benjaminiana. Según Walter Benjamin el concepto de progreso constituye un lastre para la historia, ya que la convierte en un proceso inacabable e incesante, que ofrece una versión prefigurada del futuro casi providencial (Benjamin 1989). En contraposición a este historicismo positivista, Benjamin plantea el materialismo histórico crítico, donde el análisis de los procesos históricos debe estar sometido a ciertas exigencias de prognosis (Benjamin 2003). Desde esta perspectiva, el progreso es un huracán que nos empuja inexorablemente hacia el futuro dejando a su paso 'una catástrofe única que amontona incansablemente ruina tras ruina' (Benjamin 1989: 183).

En la película se plantea explícitamente esta visión negativa del progreso de la mano de Teo, uno de los personajes neoluditas que se rebelan contra el control tecnológico de la Corporación. Esta visión distópica del progreso plantea contra-sociedades, es decir, 'visiones cruelmente grotescas de sociedades que se proclaman como ideales $\mathrm{y}$, al mismo tiempo, amarga sátira del orden existente' (Baczko 1999: 83). El objetivo es deconstruir los discursos e imaginarios tecnófilos acríticos y complacientes con los ofrecimientos del capitalismo (Adame 2011: 557), que propician la instrumentalización de las nuevas tecnologías como un nuevo dispositivo de control con el que favorecer la gubernamentalidad (Foucault 1991).

El neoludismo entronca con la concepción negativa de progreso de Benjamin y, además de quererfrenarel avance de las nuevas tecnologías, se opone a la globalización y al capitalismo. Durante el film se citan algunos fragmentos del manifiesto contra la tecnología, titulado $\mathrm{La}$ sociedad industrial y su futuro (Kaczynski 1995). Theodore John Kaczynski es un matemático graduado en Harvard que se convierte en un neoludista extremista. Recibe el nombre de Unabomber del FBI debido a su actividad terrorista centrada en el envío de bombas a universidades y aviones estadounidenses (University and Airline Bomber).

Según el manifiesto, el progreso, de la mano de la industrialización y el desarrollo tecnológico, 
somete a los seres humanos a indignidades cada vez mayores, conforme avanza, por lo que hay que acabar con las bases económicas y tecnológicas que sustentan al sistema antes de que desencadenen un colapso social. De este modo, el manifiesto tiene carácter premonitorio, ya que aparece pocos años antes de la crisis argentina y sirve de argumentario a los protagonistas tecnófobos. Como preámbulo a la escena en que se ataca a la Corporación, Teo comienza a leer el principio del manifiesto de Unabomber:

La Revolución Industrial y sus consecuencias han sido un desastre para la raza humana. Ha aumentado enormemente la expectativa de vida de aquellos de nosotros que vivimos en países 'avanzados', pero ha desestabilizado la sociedad, ha hecho la vida imposible, ha sometido a los seres humanos a indignidades, ha conducido a extender el sufrimiento psicológico (en el tercer mundo también el sufrimiento físico) y ha infligido un daño severo en el mundo natural. El continuo desarrollo de la tecnología empeorará la situación. Ciertamente someterá a los seres humanos a grandes indignidades e infligirá gran daño en el mundo natural, probablemente conducirá a un gran colapso social y al sufrimiento psicológico, y puede que conduzca al incremento del sufrimiento físico incluso en países 'avanzados' (Kaczynski 1995).

Esta narración se produce durante una secuencia, elaborada con imágenes no diegéticas, que ponen de manifiesto la presencia de una exterioridad en la película. Como señala Aguilar, este 'bajar la línea' desvela la acción pedagógica, pero también muestra la línea que la película extiende hacia el exterior: 'el personaje ético no habla dentro de la historia sino que tiene el privilegio de poder juzgarla desde fuera' (Aguilar 2006: 26).

En este sentido, cabe destacar que la tecnología per se no aparece representada de forma negativa en la película, lo que desencadena sus efectos perniciosos es el mal uso que hacen de ella los humanos. Esta crítica queda patente cuando se contrapone la forma de vivir de los habitantes de Marte y de la Tierra.

Por un lado, los marcianos disfrutan de forma pacífica de su existencia en un mundo avanzado tecnológicamente donde no hay desigualdades y la tecnología es un bien común. Esta circunstancia se constata con la afirmación de uno de los componentes de la Corporación: 'la tecnología [en Marte] es accesible a todos por igual'. Asimismo, durante el plano secuencia que muestra cómo viven los habitantes de Marte, se puede observar que la tecnología está al servicio del bienestar de la población, ya que solo trabajan las máquinas, mientras que los marcianos disfrutan del tiempo libre de manera harmónica: paseando, jugando al aire libre, viendo la televisión o bailando.

Por el otro lado, los terrícolas habitan en un planeta lleno de desigualdades, donde hay marginalidad, pobreza y violencia. En contraposición a Marte, en la Tierra se utilizan las nuevas tecnologías en provecho de unos pocos. En este sentido, observamos que la Corporación decide regalar las computadoras personales a todo el mundo como herramienta para someter a los ciudadanos y controlar la economía mundial: 'nuestra estrategia global ha sido un suceso, hemos logrado una penetración del $98 \%$ en los mercados del Mundo'. El uso instrumental que hace la Corporación de la tecnología se denuncia también a través de la interpelación de Teo: '¿No se dan cuenta que estamos cayendo en su trampa tecnológica?'.

En definitiva, la tecnología es presentada en la película como el caballo de Troya del sistema neoliberal para someter a la población mundial. Encontramos esta metáfora en la última escena, cuando el señor Tecnología destruye el planeta 
Tierra, gracias a un componente explosivo introducido de forma secreta en todas las computadoras.

\section{Conclusiones}

Aguantar es hoy cosa de los pocos poderosos que, Dios lo sabe, son menos humanos que muchos; en el mayor de los casos son más bárbaros, pero no de la manera buena. Los demás en cambio tienen que arreglárselas partiendo de cero y con muy poco. Lo hacen a una con los hombres que desde el fondo consideran lo nuevo como cosa suya y lo fundamentan en atisbos y renuncia. En sus edificaciones, en sus imágenes y en sus historias la humanidad se prepara a sobrevivir, si es preciso, a la cultura. Y lo que resulta primordial, lo hace riéndose (Benjamin 1989: 173).

Las palabras de Walter Benjamin describen perfectamente el leitmotiv de la película y podrían servir como sinopsis de la misma. Mercano el marciano surge en pleno proceso de crisis y renovación de la animación argentina en confluencia con la crisis de 2001. Al igual que sucede en el NCA (Page, 2009) y en la historieta realista de este periodo (Gago 2016), existe una fijación por mostrar la cruda realidad de la situación social en que se encuentran inmersos los argentinos, haciendo especial hincapié en las imágenes de la crisis que contienen un enorme poder simbólico.

No obstante, a diferencia del NCA, que deja al margen la demanda política y la identitaria (Aguilar 2006: 23), la película hace pedagogía y apunta explícitamente a los elementos causantes de la crisis, al tiempo que realiza una fuerte autocrítica de la sociedad argentina en el marco de la globalización. Si Alejandro Grimson comienza su artículo con la frase 'la Argentina ha sido deconstruida por el neoliberalismo' (2004: 177), el epílogo de Mercano el marciano va más allá: 'la Argentina ha sido destruida por el neoliberalismo'. Esta destrucción se plantea en el ámbito político, social y económico, pero se materializa con la destrucción física de toda la humanidad.

Así entonces, la clase política no aparece reflejada en la historia, ni siquiera supeditada a la voluntad del poder económico: no existe. El control de la sociedad está en manos de la Corporación, una organización empresarial sin escrúpulos que pone rostro a la inmaterialidad de la globalización y el poder económico mundial. Esta representación negativa de las multinacionales se instala con fuerza en el imaginario social de la crisis argentina. En este sentido, como señala Joanna Page, 'la imagen surgió de una Argentina saqueada por multinacionales y luego abandonada a su suerte por la comunidad internacional'3 ${ }^{3}$ (2009: 110).

Otro elemento que destaca en la película es el rol subversivo de la violencia, que queda legitimada como una herramienta liberadora contra el grupo opresor que ostenta el poder. Este matiz es importante, ya que las acciones violentas que se reproducen en el NCA quedan restringidas al ámbito de la marginalidad entre personajes de las clases populares, como un instrumento para la supervivencia o como simples arranques incontrolados de ira (Aguilar 2006).

Asimismo, el progreso tecnológico aparece señalado directamente por los personajes denuncialistas como coadyuvante del triunfo global del neoliberalismo para someter a la raza humana. Esta visión distópica es una herramienta utilizada para 'desmitificar las promesas del futuro que trabajan en la profundidad

\footnotetext{
Traducción del autor.
} 
del presente' (Baczko 1999: 88) desde una perspectiva neoludita que recoge algunos principios de los movimientos antiglobalización y denuncia que la tecnología es un instrumento de dominación del poder económico.

En este imaginario social de la crisis, junto al mercado y la tecnología, la humanidad aparece señalada como corresponsable de la situación. La película lanza una mirada impiadosa sobre la actitud acomodaticia de la sociedad ante el sometimiento económico. Los ciudadanos han sucumbido bajo un consumismo voraz, que los aliena, los aísla y los desactiva políticamente, quedando inutilizados como actores sociales. Al igual que sucede en el cine argentino contemporáneo, la película se centra en la atomización de lo social y en la imposibilidad de restablecer la acción colectiva(Page2009). Eneste sentido, la película coincide con el planteamiento de Sloterdijk en el Desprecio de las masas:

La masa posmoderna es una masa carente de potencial alguno, una suma de microanarquismos y soledades que apenas recuerda la época en la que ella - excitada y conducida hacia sí misma a través de sus portavoces y secretarios generales - debía y quería hacer historia en virtud de su condición de colectivo preñado de expresividad (Sloterdijk 2002: 18).

Finalmente, otro elemento que se pone de manifiesto es la constatación de que la crisis destruye el mito de la excepcionalidad argentina en el imaginario colectivo. La película muestra las consecuencias de la pauperización en el mismo corazón del país: miseria, saqueos, violencia, mendicidad, etc. El estado de calamidad nacional y la desesperación de una gran parte de la población argentina se resumen en la frase: 'Esto no da para más, vámonos a Barcelona' afirmación que 'se escucha como un epitafio a los años menemistas' (Manrupe 2004: 116). De este modo, Mercano muestra una situación irreversible y niega siquiera la esperanza utópica de un futuro mejor (Cuña 2000). Discurso que entronca con la producción cinematográfica y literaria de este periodo, donde prevalece la representación de un mundo arruinado, en el que no hay lugar para la esperanza de la renovación ni una posible apertura hacia el futuro (Rodríguez Pérsico 2015; Page 2009; Gorelik 2003).

\section{Bibliografía}

Adame, M. A. 2011. "En defensa del paradigma Homo. Crítica y ejemplificaciones del discurso y del imaginario tecnocibernético antihumanista". La arquitectura del sentido II. La producción y reproducción en las prácticas semiótico-discursivas. Haidar, J. y Sánchez Guevara, G. (Eds.). México DF: INAH. 527-561.

Aguilar, G. M. 2006. Otros mundos: ensayo sobre el nuevo cine argentino. Buenos Aires: Santiago Arcos.

Amado, A. M. 2009. La imagen justa: cine argentino y política, 1980-2007. Buenos Aires: Colihue.

Baczko, B. 1999. Los imaginarios sociales. Buenos Aires: Nueva Visión.

Baeza, M. A. 2008. Mundo real, mundo imaginario social. Teoría y práctica de sociología profunda. Santiago de Chile: RIL. 2003. Imaginarios Sociales. Apuntes para la discusión teórica y metodológica. Concepción: Universidad de Concepción.
Serie monografías.

2000. Los Caminos Invisibles de la Realidad Social. Ensayo de sociología profunda sobre los imaginarios sociales. Santiago de Chile: RIL.

Baeza, M. A. y Silva, G. 2009. "Imaginarios sociales del Otro: el personaje del forastero en Chile (de 1845 a nuestros días)". Sociedad Hoy 17. 29-38.

Benjamin, W. 2003. La obra de arte en la época de su reproductibilidad técnica. México: Itaca. 1989. Discursos interrumpidos I. Buenos Aires: Taurus.

Castoriadis, C. 2007. La institución imaginaria de la sociedad. Buenos Aires: Tusquets.

1999. Figuras de lo pensable. Madrid: Cátedra.

1991. "Lógica, imaginación, reflexión". El inconsciente y la ciencia. Dorey, R. (Ed.). Buenos Aires: Amorrortu. 21-50. 
Cuña, I. 2000. Identidad y Utopía. Neuquén: EDUCO.

Díaz, C. 2015. Fisuras en el sentido. Luchas populares y luchas simbólicas. Córdoba, Argentina: Recovecos.

Foucault, M. 1991. "La gubernamentalidad". Espacios de poder. Donzelot, J., Grignon, C., Gaudemar, J.-P., Muel, F. y Castel, R. (Eds.). Madrid: Endymion. 9-26.

Gago, S. 2016. "Carne Argentina: las representaciones de la crisis de 2001 en la historieta". Miguel Hernández Communication Journal 7: 139-168. Disponible en:

http://rev.innovacionumh.es/index.php?journal=mhcj\&page=articl e\&op=view\&path\%5B\%5D=132\&path\%5B\%5D=255

Godfrid, F. 2009. "El empleo del tiempo". Grupokane: 1-11. Disponible en: http://www.grupokane.com.ar/index. php?option $=$ com_content\&view $=$ article\&id $=226$ :artentrevbgras so\&catid=39: catanimacion\&ltemid=29 (consultado en enero de 2018).

Gorelik, A. 2003. "Mala época: Los imaginarios de la descomposición social y urbana en Buenos Aires". Imágenes de los noventa. Birgin, A. y Trímboli, J. (Comps.). Buenos Aires: Zorzal. 19-46.

Grimson, A. 2004. "La experiencia argentina y sus fantasmas". La cultura en las crisis latinoamericanas. Grimson, A. (Comp.). Buenos Aires: CLACSO. 177-193.

Imbert, G. 2006: "Violencia e imaginarios sociales en el cine actual”. Versión 18: 27-51.

Jäger, S. 2003. "Discurso y conocimiento: aspectos teóricos y metodológicos de la crítica del discurso y del análisis de dispositivos". Métodos de análisis crítico del discurso. Wodak, R. y Meyer, M. (Comps.). Barcelona: Gedisa. 61-100.

Jameson, F. 2002. El giro cultural. Buenos Aires: Manantial. 1995. The geopolitical aesthetic: cinema and space in the world system. Londres: Indiana University Press.

Kaczynski, T. J. 1995. "La sociedad industrial y su futuro". Disponible en: http://www.sindominio.net/ecotopia/textos/ unabomber.html (consultado en noviembre de 2017).

Kirchheimer, M. 2012. "Caminos del cine de animación argentina contemporánea. Cruces entre representaciones e historietistas". II Congreso Internacional Viñetas Serias: narrativas gráficas: lenguajes entre el arte y el mercado. Buenos Aires. 1-11.

Mayorga Rojel, A. J., del Valle Rojas, C. y Browne Sartori, R. 2013. "El imaginario social de la acción colectiva de protesta y la crisis Argentina de 2001, en el discurso de la prensa en Chile". Polis (Santiago) 12 (34): 491-518.

Manrupe, R. 2004. Breve historia del dibujo animado en la Argentina. Buenos Aires: Libros del Rojas.

Page, J. 2009. Crisis and Capitalism in Contemporary Argentine Cinema, Londres: Duke University Press.

Pelli, M. S. 2012. "Fantasías Animadas Argentinas". Fuera de cuadro: discursos audiovisuales desde los márgenes. Triquell, $\mathrm{X}$., Ruiz, S. (Eds.). Villa María: Eduvim. 55-68.

Rodríguez Pérsico, A. 2015. "La crisis como ruina. Literatura argentina de principios de siglo XXI". Cultural Narratives of Crisis and Renewal (CRIC) seminars, Amsterdam.

Salinas, C., Stange, H. y Santa Cruz, E. 2013. "Apuntes para la discusión de la relación cine-historia en la cinematografía chilena de ficción". Revista Austral de Ciencias Sociales 25: 115-127. Disponible en: http://mingaonline.uach.cl/scielo. php?script=sci_arttext\&pid=S0718-17952013000200006\&lng=es \&nrm=iso

Sloterdijk, P. 2002. El desprecio de las masas: ensayo sobre las luchas culturales de la sociedad moderna. Valencia: Pre-textos.

Sorlin, P. 1991. "Historia del cine e historia de las sociedades". Film-Historia 1 (2): 73-87.

Svampa, M. 2005. La sociedad excluyente: la Argentina bajo el signo del neoliberalismo. Buenos Aires: Taurus.

Van Dijk, T. A. 2003. "La multidisciplinariedad del análisis crítico del discurso: un alegato a favor de la diversidad". Métodos de análisis crítico del discurso. Wodak, R. y Meyer, M. (Comps.). Barcelona: Gedisa. 143-178.

Verón, E. 1998. La semiosis social: Fragmento de una teoría de la discursividad. Barcelona: Gedisa.

Williams, R. 1997. Marxismo y literatura. Barcelona: Península. 